\title{
Anticorpos policlonais em dietas com alta inclusão de concentrado para bovinos confinados
}

\author{
Polyclonal antibodies for feedlot cattle fed high-concentrate diets
}

\author{
Danilo Domingues Millen ${ }^{\mathrm{I}^{*}}$ João Ricardo Ronchesel ${ }^{\mathrm{II}}$ Fernando Salvador Parra ${ }^{\mathrm{II}}$ \\ Rodrigo Dias Lauritano Pacheco ${ }^{\mathrm{II}}$ Cyntia Ludovico Martins ${ }^{\mathrm{III}}$ Mário De Beni Arrigoni ${ }^{\mathrm{I}}$
}

\section{- REVISÃO BIBLIOGRÁFICA -}

\section{RESUMO}

Dentre as alternativas para substituir o uso de ionóforos classificados como antibiótico por alguns comitês, a utilização de anticorpos policlonais classificados como promotores de crescimento naturais tem se mostrado alternativa interessante e economicamente eficiente. Recentes estudos demonstraram pontos positivos na utilização desse aditivo em dietas com alta inclusão de ingredientes concentrados para bovinos confinados, traduzido por melhora de desempenho e saúde ruminal, em alguns casos, semelhantes à monensina sódica. No entanto, alguns pontos dessa nova tecnologia ainda devem ser elucidados, entre eles, a possível perda de atividade da forma sólida de apresentação do preparado e a diminuição do rendimento de carcaça encontrado em alguns estudos. Contudo, a presente revisão destaca a possibilidade de substituição da monensina sódica por anticorpos policlonais sem resultar em diminuição de desempenho e de rentabilidade para a bovinocultura de corte brasileira.

Palavras-chave: acidose, alternativa, antibióticos, ionóforos.

\section{ABSTRACT}

Among alternatives to replace ionophores, which are classified as antibiotics by some committees, the feeding of polyclonal antibodies have shown an interesting and economically efficient alternative. Recent studies have demonstrated some advantages of adding polyclonal antibodies into high-concentrate diets for feedlot cattle, showed by increased performance and ruminal health, in some cases similar to sodium monensin. However, there are blind spots of this innovated technology that still need to be elucidated, as example, if the dry form of the preparation is inactivated and decreased carcass-dressing percentage. All in all, this review demonstrates the possibility of replacing sodium monensin by this feed additive without negatively impacting animal performance and profit of cattle feeders in Brazil.

Key words: acidosis, alternative, antibiotics, ionophores.

\section{INTRODUÇÃO}

Os ionófros são utilizados na nutrição de ruminantes, devido à habilidade em melhorar a eficiência alimentar e reduzir os riscos de acidose e timpanismo (MARINO et al., 2011; BERGEN \& BATES, 1984). No entanto, a legislação da União Europeia baniu o uso de antibióticos ionóforos na nutrição animal em janeiro de 2006 e, desde então, a indústria de carne e leite da União Europeia vem ativamente buscando alternativas para reduzir a acidose nos confinamentos sem a utilização de antibióticos ionóforos.

Uma das alternativas para substituir os ionóforos, e que não tinha recebido muita atenção até o presente momento, é a produção e uso de anticorpos policlonais por meio da técnica de imunização. O conceito de imunização como ferramenta para atingir maior eficiência na fermentação ruminal e assim melhorar o desempenho animal é relativamente recente (NEWBOLD et al., 2001; HARDY, 2002; BERGHMAN \& WAGHELA, 2004).

A base desse mecanismo é o reconhecimento de corpos estranhos no organismo (antígenos), ativação dos leucócitos e engajamento do mecanismo direto para remoção do patógeno. Quando os macrófagos da corrente sanguínea do hospedeiro encontram moléculas estranhas (antígenos), estes respondem englobando-as. Esse evento é mediado

\footnotetext{
ICurso de Zootecnia, Universidade Estadual Paulista (UNESP), 17900-000, Dracena, SP, Brasil. E-mail: danilomillen@dracena.unesp.br. *Autor para correspondência.

IIDepartamento de Melhoramento e Nutrição Animal, Faculdade de Medicina Veterinária e Zootecnia (FMVZ), UNESP, Botucatu, SP, Brasil. IIIDepartamento de Produção Animal, FMVZ, UNESP, Botucatu, SP, Brasil.
} 
pelas células $\mathrm{T}$, que estabelecem uma corrente de respostas, o que resulta no estímulo das células $\mathrm{B}$. As células B produzem proteínas chamadas anticorpos, os quais se ligam às moléculas estranhas. Essa ligação entre anticorpo e antígeno causa a destruição do invasor por fagocitose (GOLDSBY et al., 2000).

Dessa forma, o mecanismo de formação do produto a base de anticorpos policlonais para uso na alimentação de bovinos se dá da seguinte maneira: galinhas são vacinadas com pequenas doses de imunógenos de bactérias ruminais vivas (Streptococcus bovis, Fusobacterium necrophorum, Lactobacillus spp. entre outras) e logo desenvolvem anticorpos específicos contra essas bactérias. Esses anticorpos passam, através de mecanismos fisiológicos das aves para a gema do ovo. Essa gema é então utilizada para se fazer o produto batizado de Preparado de Anticorpos Policlonais (PAP) com anticorpos específicos, os quais têm como alvo eliminar, do meio ruminal dos bovinos, bactérias cujos produtos da fermentação são indesejáveis (SHIMIZU et al., 1988). O PAP testado nos experimentos que serão descritos nessa revisão tiveram diferentes formulações, as quais incluíram anticorpos contra as bactérias S. bovis, Lactobacillus spp. (ambos microorganismos produtores de ácido lático e precursores da acidose ruminal), $\boldsymbol{F}$. Necrophorum (bactéria responsável pela formação de abscessos hepáticos), Salmonella, Escherichia coli e as três maiores proteolíticas presentes no rúmen: Clostridium aminophilum e sticklandii e Peptostreptococcus spp.; além de anticorpos contra Endotoxinas (toxina advinda de bactérias Gram + que deprimem o sistema imune do animal em situações de baixo $\mathrm{pH}$ ruminal). O PAP é produzido pela Camas Incorporated (Le Center, Minnesota, EUA) e tem sido testado para provar sua eficiência em reduzir as populações das bactérias ruminais citadas acima.

$\mathrm{O}$ uso potencial de imunoglobulinas $\mathrm{Y}$ (IgY) de gemas de ovos como aditivo alimentar foi investigado por SHIMIZU et al. (1992), os quais reportaram que as IgY tinham estabilidade no meio ruminal por terem sido testadas sob várias condições de temperatura, e terem provado ser resistentes à proteólise e a faixas de $\mathrm{pH}$ ao redor de 4,5; o que indica que esses tipos de compostos poderiam ter grande potencial como aditivos alimentares para bovinos alimentados com dietas altamente energéticas, por resistirem às condições adversas impostas pelo sistema gastrintestinal.
Prevenção de acidose e abscessos hepáticos

DILORENZO et al. (2006) avaliaram a administração de dois PAP, um contra Streptococcus bovis (PAP-Sb) e outro contra Fusobacterium necrophorum (PAP-Fn), bactérias precursoras da acidose ruminal e abscesso hepático, respectivamente. Foram observadas reduções das populações desses micro-organismos quando novilhos foram alimentados com dietas que continham alta inclusão de ingredientes concentrados. A alta especificidade do anticorpo foi observada porque ele não afetou as populações de outras bactérias testadas, diferentemente do encontrado com a administração de monensina sódica (MON), a qual reduz a população de micro-organismos Gram + e, concomitantemente, o fluxo de proteína microbiana para o intestino (GOODRICH et al., 1984). Tal fato pode demonstrar a vantagem do PAP sobre a MON, tendo em vista que a proteína microbiana é uma fonte de proteína de alto valor biológico de extrema importância para os ruminantes.

No mesmo estudo de DILORENZO et al. (2006), a adição de PAP-Sb na dieta foi eficiente em aumentar o pH ruminal $(6,08)$, em comparação ao grupo controle sem aditivo $(5,67)$; no entanto, não houve efeito $(\mathrm{P}>0,05)$ do fornecimento do PAPFn, MON + tilosina (300mg dia- e 90mg dia ${ }^{-1}$, respectivamente) ou a administração de ambos os tratamentos sobre o pH ruminal. Em estudo posterior, DILORENZO et al. (2008) relataram que a adição de PAP-Fn diminuiu a incidência de abscessos hepáticos em animais que receberam dietas com alta inclusão de concentrado, sendo que os animais que receberam esse aditivo apresentaram menor porcentagem de abscessos hepáticos $(9,7 \%)$ em relação ao grupo controle $(18,3 \%)$ ou com PAP-Sb (11,1\%). Esses dados revelam que a utilização do PAP proporcionou aos animais imunizados melhor ambiente para fermentação e desenvolvimento de micro-organismos benéficos.

BLANCH et al. (2009) estudaram os efeitos do PAP que continha anticorpos contra as bactérias S. bovis, F. necrophorum, E. coli, Clostridium aminophilum e sticklandii e Peptostreptococcus spp. em novilhas com oferta à vontade de feno ou feno mais adição de PAP $\left(10 \mathrm{ml}\right.$ animal $\left.{ }^{-1} \mathrm{dia}^{-1}\right)$ durante 10 dias, seguidas de aumento diário da quantidade de concentrado $\left(2,5 \mathrm{~kg}\right.$ animal $\left.{ }^{-1} \mathrm{dia}^{-1}\right)$ do dia 11 ao 15 , atingindo a quantidade de $12,5 \mathrm{~kg}$ animal ${ }^{-1} \mathrm{dia}^{-1}$ até estas entrarem em acidose. Os autores relataram que apenas 50\% das novilhas do tratamento com PAP apresentaram acidose, em comparação aos 83\% do grupo controle ao redor de 5,25 $\pm 0,17$ dias após o início do desafio. Adicionalmente, as novilhas que receberam PAP apresentaram maior $\mathrm{pH}$ ruminal nos 
dias 6 (6,7 vs. 6,11), 8 (6,54 vs. 5,95) e 9 (7,26 vs. $6,59)$ após o início do desafio em relação ao grupo controle, respectivamente. Desse modo, novamente o PAP foi efetivo em reduzir o risco de acidose, pois os animais suplementados, apesar de apresentarem maior concentração total de ácidos graxos de cadeia curta (124 vs. $\left.114 \mathrm{mmol} \mathrm{L}^{-1}\right)$, apresentaram maior $\mathrm{pH}$ ruminal $(6,54$ vs. 5,95) e maior concentração de ácido acético (90,3 vs. $\left.81,8 \mathrm{~mol} 100 \mathrm{~mol}^{-1}\right)$.

Em estudo brasileiro, com vacas Girolandas canuladas, MARINO et al. (2011) relataram que a suplementação com PAP que continha anticorpos contra as bactérias $\boldsymbol{S}$. bovis, $\boldsymbol{F}$. necrophorum, E. coli, Clostridium aminophilum e sticklandii e Peptostreptococcus spp à dose de $10 \mathrm{ml}$ animal ${ }^{-1}$ dia $^{-1}$ foi tão efetiva em controlar o $\mathrm{pH}$ ruminal em dietas de alta inclusão de concentrado quanto a MON (5,95 vs. 5,99) 4h após a alimentação, sendo esses valores maiores que os apresentados pelo grupo controle $(5,65)$. Entretanto, ao longo do dia, a inclusão do PAP não alterou o tempo em que o pH ruminal permaneceu abaixo de 6,0. Em outro estudo subsequente, BASTOS et al. (2012) observaram que níveis crescentes nas doses de PAP na forma sólida $\left(0 ; 1,5 ; 3,0\right.$ e 4,5g animal-1 dia $\left.^{-1}\right)$ contra $\boldsymbol{S}$. bovis, $\boldsymbol{F}$. necrophorum, $\boldsymbol{E}$. coli e várias cepas de bactérias proteolíticas não alteraram o pH ruminal de vacas fistuladas, alimentadas com dietas de alto concentrado. As razões pelas quais não houve efeitos significativos da inclusão de PAP neste estudo permanecem incertas. Possivelmente, o processo de transformação do preparado da forma líquida para sólida (spray dryer) seja o causador da perda de atividade do PAP.

Por outro lado, OTERO (2008) observou aumento na degradabilidade potencial do FDN, quando o mesmo PAP utilizado por MARINO et al. (2011) foi administrado em comparação com a MON. Da mesma forma, OTERO (2008) apontou aumento de 93,65\% na contagem relativa de protozoários Isotricha em relação ao grupo controle. O efeito do PAP no aumento de Isotricha pode demonstrar a ação desse produto na diminuição do número de bactérias responsáveis pela acidificação do ambiente, tornando este favorável à proliferação de bactérias (fonte de substrato dos protozoários) e também para os protozoários.

SHU et al. (2000), os quais avaliaram a imunização ativa contra bactérias precursoras da acidose ruminal, observaram que ovinos vacinados contra $\boldsymbol{S}$. bovis apresentaram menores escores de diarreia severa, quando comparados aos animais controle (não-vacinados com PAP-Sb) e ainda relataram menor aumento no volume das células do sangue em animais que receberam PAP-Sb e que foram alimentados com dieta contendo 90\% de concentrado. Isso representa menor perda de fluído intravascular, o que é associado a $\mathrm{pH}$ sanguíneo mais elevado, o qual reflete em maiores excessos de bases e bicarbonatos no sangue, e implica controle homeostático mais eficiente e menor risco de acidose ruminal e metabólica.

A ingestão de matéria seca (IMS) após a mudança de dieta pode servir como indicativo da presença de acidose. MILLEN et al. (2010) não observaram $(\mathrm{P}>0,05)$ efeito principal dos aditivos alimentares (PAP e MON) sobre a IMS durante os quatro primeiros dias de mensuração após a introdução de nova dieta. Entretanto, foi encontrada $(\mathrm{P}<0,01)$ interação entre aditivos alimentares, fases de mensuração (crescimento e terminação) e dias de mensuração para IMS. Na fase de crescimento, animais que receberam MON não apresentaram diferenças $(\mathrm{P}>0,05)$ na IMS nos quatro primeiros dias de mensuração (dia $1=5,78 \mathrm{~kg}$; dia $2=6,00 \mathrm{~kg}$; dia 3=5,81kg; dia 4=5,85kg); por outro lado, em bovinos que receberam a dieta que continha PAP, foi observado $(\mathrm{P}<0,05)$ crescente aumento da IMS nos 4 dias de mensuração (dia 1=5,8kg; dia 2=6,11kg; dia 3=6,68kg; dia 4=6,87kg), apresentando-se ainda maiores $(\mathrm{P}<0,05)$ IMS $(6,68 \mathrm{~kg}$ e $6,87 \mathrm{~kg})$ que animais suplementados com MON nos dias 3 e 4 (5,81kg e 5,86kg). Tal padrão crescente de IMS nos animais que recebiam o PAP pode indicar o melhor controle do $\mathrm{pH}$ ruminal, haja vista que, em situações de dietas com alta energia, o controle da IMS ocorre por sinais químicos (baixo pH). Também foi encontrada interação entre os aditivos alimentares e fase de mensuração para oscilação da IMS, sendo que animais que receberam PAP apresentaram maior $(\mathrm{P}<0,01)$ variação na IMS na fase de crescimento que animais suplementados com MON (0,339kg dia-1 vs. 0,243kg dia-1). A explicação dessa maior oscilação da IMS nos animais tratados com o PAP deve-se ao padrão crescente de IMS, após a mudança da dieta de adaptação para a de crescimento. No entanto, não foi observada diferença $(\mathrm{P}>0,05)$ entre os aditivos alimentares na fase de terminação $\left(0,298 \mathrm{~kg} \mathrm{dia}^{-1} \mathrm{vs}\right.$. $\left.0,238 \mathrm{~kg} \mathrm{dia}^{-1}\right)$.

PACHECO et al. (2012) analisaram o perfil metabólico sanguíneo de bovinos confinados que receberam MON ou PAP contra as bactérias ruminais S. bovis, F. necrophorum, E. coli e várias cepas de bactérias proteolíticas. As amostras foram coletadas 15 dias após a introdução da nova dieta. Não foram observadas diferenças entre os aditivos alimentares para o $\mathrm{pH}$, bicarbonatos, pressão parcial de $\mathrm{CO}_{2}$, 
total de $\mathrm{CO}_{2}$ (TCO2), excesso de bases no sangue (BEB) e no fluído extracelular (BEECF) quando os animais foram promovidos da dieta de adaptação com $58 \%$ de concentrado até a de terminação com $85 \%$ de concentrado $(58 \% \rightarrow 73 \% \rightarrow 82 \% \rightarrow 85 \%$ de concentrado). Do mesmo modo, não foram encontradas diferenças entre os aditivos alimentares em termos de flutuação na ingestão de matéria seca, mensurada nos quatro primeiros dias após a introdução de nova dieta (PACHECO et al., 2012). Por outro lado, MILLEN et al. (2010) observou $(\mathrm{P}<0,01)$ efeito principal dos aditivos alimentares sobre os teores sanguíneos de bicarbonato, $\mathrm{TCO}_{2}$ e BEECF, em que bovinos que receberam PAP apresentaram maiores concentrações desses metabólitos no sangue. Ainda, foi encontrada interação entre aditivos alimentares e grupos genéticos para pH sanguíneo, já que animais Brangus que receberam PAP apresentaram maiores $(\mathrm{P}<0,01)$ valores de $\mathrm{pH}(7,457)$ que Brangus suplementados com MON $(7,435)$; no entanto, não foi observada diferença $(\mathrm{P}>0,05)$ no $\mathrm{pH}$ sanguíneo entre bovinos Nelore alimentados com PAP ou MON (7,439 e 7,445; respectivamente). Foram encontradas também interações $(\mathrm{P}<0,05)$ entre aditivos alimentares e fases de mensuração para $\mathrm{pH}$ do sangue. Animais que receberam PAP apresentaram maiores $(\mathrm{P}<0,01)$ valores de $\mathrm{pH}$ na fase de adaptação que animais suplementados com MON (7,427 vs. $7,400)$. No entanto, não foi observada diferença $(\mathrm{P}>0,05)$ entre os aditivos alimentares nas fases de crescimento e terminação.

\section{Lesões ruminais}

PACHECO et al. (2012) relataram menor incidência de rumenites em bovinos que receberam o PAP contra as bactérias $\boldsymbol{S}$. bovis, $\boldsymbol{F}$. necrophorum, E. coli e várias cepas de bactérias proteolíticas, quando estes foram comparados com os animais que receberam MON. Por outro lado, MILLEN et al. (2009) não encontraram efeito principal dos aditivos alimentares (PAP e MON), nem interação significativa $(\mathrm{P}>0,05)$ entre grupos genéticos (Brangus e Nelore) e aditivos alimentares com relação à incidência de rumenites. Já SARTI et al. (2009) observaram que a inclusão do PAP contra as bactérias $S$. bovis, $F$. necrophorum, Lactobacillus spp., $\boldsymbol{E}$. coli e endotoxinas na dieta não melhorou a superfície de absorção da parede ruminal. No entanto, a suplementação com MON mostrou ser efetiva em aumentar a superfície de absorção por $\mathrm{cm}^{2}$ de parede do rúmen, quando foram comparados aos animais que não receberam MON (24,92 vs. 19,45 $\mathrm{cm}^{2}$ ). No estudo de RODRIGUES et al. (2013), utilizou-se o mesmo
PAP do estudo de SARTI et al. (2009), e a adição de PAP aumentou a área de superfície de absorção por $\mathrm{cm}^{2}$ de parede ruminal, quando comparados aos animais que não receberam PAP (21,10 vs. $\left.17,30 \mathrm{~cm}^{2}\right)$. Por outro lado, a suplementação com leveduras não provocou alterações $(\mathrm{P}>0,05)$ no epitélio ruminal. Quando se comparou os animais suplementados com MON com os demais tratamentos individualmente pelo teste de Dunnett, não foi observada $(\mathrm{P}>0,05)$ diferença para a superfície de absorção, quando a comparação foi feita com os animais que receberam PAP (25,82 vs. 23,42 $\left.\mathrm{cm}^{2}\right)$, porém foi significativa quando comparado aos animais que receberam leveduras (25,82 vs. $\left.15,99 \mathrm{~cm}^{2}\right)$. No entanto, não houve efeito dos aditivos utilizados (PAP, leveduras e MON) sobre a incidência de rumenites, a qual foi muito baixa neste estudo $(1,52)$, considerando-se escala de 0 (sem lesões) a 10 (lesões ulcerativas e rúmen totalmente comprometido). A maior superfície de absorção do epitélio ruminal pode indicar maior absorção de ácidos graxos de cadeia curta e ainda menor extensão de lesões (rumenites).

Desempenho e características de carcaça e carne DILORENZO et al. (2008) avaliaram a administração de PAP-Sb, PAP-Fn e a administração de ambos em novilhos Angus que recebiam dietas de alta proporção de grãos. Os animais tratados com PAP-Sb e PAP-Fn apresentaram maiores pesos finais (559kg e $558 \mathrm{~kg}$, respectivamente) que aqueles não alimentados com esses aditivos (542kg) ou alimentados com ambos os aditivos (550kg). Efeitos sobre o peso final, de acordo com os autores, foram devido ao maior ganho de peso diário dos novilhos alimentados com PAP-Sb ou PAP-Fn $(1,85 \mathrm{~kg}$ e $1,84 \mathrm{~kg}$, respectivamente) em comparação ao animais alimentados com PAP-Sb+PAP-Fn (1,79kg) ou sem nenhum dos aditivos (1,78kg). Não foram observados efeitos em relação à IMS quando o PAP foi administrado. Novilhos Angus alimentados com PAP-Sb melhoraram a eficiência alimentar, comparados àqueles que não receberam PAP ou àqueles que receberam PAP-Sb+PAP-Fn (0,193 vs. 0,186 e 0,186 ; respectivamente). DILORENZO et al. (2008) também constataram que a alimentação com PAP-Sb aumentou o peso de carcaça quente, espessura de gordura subcutânea e melhorou a classificação das carcaças, provavelmente devido ao efeito sobre o ganho de peso diário, devido a melhorias no padrão de fermentação ruminal.

No entanto, DILORENZO et al. (2008) reportaram que bovinos que receberam o PAP-Fn apresentaram menor rendimento de carcaça que 
aqueles que não receberam o PAP contra esta bactéria (62,2 vs. 62,7\%). PACHECO et al. (2008), em estudo brasileiro, encontraram também redução no rendimento de carcaça quando bovinos receberam PAP contra $\boldsymbol{S}$. bovis, $\boldsymbol{F}$. necrophorum e várias cepas de bactérias proteolíticas, comparado à monensina (53,4 vs. 54,5\%). Razões pelas quais a suplementação de PAP-Fn provoca esse efeito negativo sobre o rendimento de carcaça e se isto está de alguma forma ligado à bactéria $\boldsymbol{F}$. necrophorum, ainda são desconhecidas. Estudos detalhados que mensurem os pesos dos órgãos viscerais e suas respectivas contribuições negativas ao rendimento de carcaça podem ajudar a elucidar tais questões.

PACHECO et al. (2012) testaram o PAP contra as bactérias ruminais $\boldsymbol{S}$. bovis, $\boldsymbol{F}$. necrophorum, $\boldsymbol{E}$. coli e várias cepas de bactérias proteolíticas sobre o desempenho de bovinos jovens com diferentes graus de sangue Zebu e relataram que animais suplementados com PAP apresentaram ganho de peso diário (1,35 vs. 1,31kg), IMS em quilos (8,37 vs. $8,14 \mathrm{~kg})$ e eficiência alimentar $(0,159$ vs. 0,160$)$ similares aos de animais suplementados com MON. Já em porcentagem do peso vivo, animais suplementados com PAP consumiram mais que aqueles suplementados com monensina sódica (2,20 vs. 2,14\%). A redução de IMS pela monensina sódica está de acordo com os diversos experimentos citados pela revisão de GOODRICH et al. (1984). Ainda, a maior IMS para os animais tratados com PAP pode ser devido ao melhor controle do $\mathrm{pH}$ ruminal, o que permite maiores ingestões em animais que recebem rações com alta inclusão de concentrados.

BARDUCCI et al. (2009) estudaram a inclusão ou não de MON ou PAP contra as bactérias S. bovis, F. Necrophorum, Lactobacillus spp., E. coli e endotoxinas em dietas com alta inclusão de concentrado para bovinos jovens Brangus em confinamento em estudo de arranjo fatorial 2x2 (inclusão ou não de PAP x inclusão ou não de MON). Os animais suplementados com MON apresentaram melhor eficiência alimentar (0,179 vs. 0,173), maiores ganhos de peso diário (1,68 vs. 1,57kg) e peso de carcaça quente $(248,46$ vs. $240,20 \mathrm{~kg})$ que aqueles não receberam MON. Por outro lado, a adição de PAP na dieta não melhorou o desempenho dos bovinos confinados (1,626 vs.1,592) nem afetou negativamente a IMS (9,16 vs. 9,08kg) e o rendimento de carcaça (52,38 vs. 52,12kg). Novamente, neste experimento, foi utilizado o PAP na forma sólida, o que contribui para a sugestão de que o processo de obtenção do preparado na forma de apresentação em pó tenha inativado os anticorpos.
Da mesma forma, RODRIGUES et al. (2013) avaliaram o efeito de diferentes aditivos alimentares sobre o desempenho de bovinos Nelore confinados em estudo com arranjo fatorial $2 \times 2+1$, em que os fatores foram a inclusão ou não de PAP (contra as bactérias ruminais $\boldsymbol{S}$. bovis, $\boldsymbol{F}$. necrophorum, E. coli e várias cepas de bactérias proteolíticas, sob a forma de apresentação sólida) ou Leveduras (Sacharomyces cerevisae) e o tratamento adicional com MON. A análise foi realizada através de contrastes ortogonais. Esses autores relataram que não houve efeito $(\mathrm{P}>0,10)$ da adição do PAP em relação ao ganho de peso médio diário, IMS em quilos e porcentagem do peso vivo e conversão alimentar. No entanto, quando se compararam os animais que consumiram MON com os dos demais tratamentos pelo teste de Dunnett, foi observado $(\mathrm{P}<0,05)$ menor custo para ganho de um quilograma de peso vivo em confinamento $(R \$ 2,62)$ que a média $(R \$ 2,79)$ dos demais tratamentos (Controle, PAP, leveduras e PAP+leveduras). Da mesma forma, o tratamento que recebeu MON apresentou maior $(\mathrm{P}<0,05)$ peso de carcaça quente $(262,26 \mathrm{~kg}$ vs. $255,61 \mathrm{~kg})$ em relação aos demais (Controle, PAP, LEV e PAP+LEV) tratamentos. No entanto, quando a monensina foi comparada diretamente com o PAP pelo teste de Dunnett, nenhuma diferença foi observada no tocante ao desempenho animal, quando um ou outro desses aditivos foram incluídos nas dietas.

Com relação às características de carne, PACHECO et al. (2008) não encontraram diferenças significativas entre bovinos que receberam PAP (contra S. bovis, F. necrophorum, E. coli e várias cepas de bactérias proteolíticas) ou MON sobre a maciez (mensurada pelos métodos do Shear Force e MFI), concentração de colesterol e lipídeos totais, no músculo Longissimus, e quantidade de gordura visceral. Da mesma forma, de acordo com PACHECO et al. (2012), bovinos jovens, com diferentes graus de sangue zebu, alimentados com PAP (contra as bactérias ruminais $\boldsymbol{S}$. bovis, $\boldsymbol{F}$. necrophorum, $\boldsymbol{E}$. coli e várias cepas de bactérias proteolíticas) ou MON, apresentaram algumas similaridades com respeito ao perfil de ácidos graxos da gordura subcutânea do músculo Longissimus. Foram observados resultados similares para os ácidos mirístico (C14:0), esteárico (C18:0), oleico (C18:1), linoleico (C18:2) e linolênico (C18:3). No entanto, para os ácidos palmítico (C16:0) e margárico (C17:0), foram encontradas maiores concentrações destes na gordura subcutânea de animais suplementados com MON. Ionóforos inibem o crescimento de bactérias Gram + e muitas dessas bactérias estão envolvidas no processo de 
biohidrogenação no rúmen, incluindo a Butyrivibrio fibrisolvens (VAN NEVEL \& DEMEYER, 1995; FELLNER et al., 1997). Assim, seria esperado que a suplementação com MON aumentasse a proporção de pelo menos alguns ácidos graxos insaturados na gordura subcutânea de bovinos suplementados, como constatado anteriormente na literatura (SAUER et al., 1998; EIFERT, 2004).

Isso poderia estar ligado de alguma forma às lipoproteínas do sangue, as quais são responsáveis pelo transporte dos ácidos graxos saturados e insaturados até os tecidos alvos. RONCHESEL et al. (2010) mensuraram as concentrações de colesterol, triglicerídeos e das lipoproteínas VLDL, LDL e HDL no sangue de bovinos Brangus confinados, que receberam dietas com inclusão ou não de MON ou PAP (contras as bactérias $\boldsymbol{S}$. bovis, $\boldsymbol{F}$. necrophorum, Lactobacillus spp., $\boldsymbol{E}$. coli e endotoxinas) e não encontraram efeito dos aditivos alimentares sobre as variáveis estudadas.

\section{Comportamento ingestivo}

MARIANI et al. (2010) reportou que animais suplementados com MON apresentaram maior número de refeições por dia $(17,03$ vs. 15,88$)$ e menor tempo de alimentação em minutos por refeição $(13,83$ vs. 15,31$)$ que animais que receberam PAP (contra as bactérias ruminais $\boldsymbol{S}$. bovis, $\boldsymbol{F}$. necrophorum, $\boldsymbol{E}$. coli e várias cepas de bactérias proteolíticas), o que indica que, como a IMS por refeição foi numericamente menor $(0,450$ vs. 0,483$)$ e animais suplementados com MON foram mais vezes ao cocho, aumentou com isso a taxa de passagem da digesta do rúmen para o omaso, e consequentemente aumentando o tempo de ruminação desses animais, o qual foi observado apenas no período de terminação. O menor tempo de alimentação por refeição e o maior número de refeições por dia em bovinos que receberam MON, provavelmente devem estar ligados à reduzida variação na IMS. BURRIN et al. (1988) e STOCK et al. (1995) reportaram reduzida variação na IMS quando MON foi fornecida a bovinos confinados. Contudo, o fato de os animais tradados com PAP ingerirem mais alimento e variar o padrão ingestivo, nesse caso, aumentando a IMS com o passar do tempo, reforça o potencial desse aditivo em controlar os surtos de acidoses sem comprometer o desempenho e saúde ruminal, como foi demonstrado nos experimentos citados nas seções anteriores.

Em relação às demais variáveis do comportamento ingestivo e às eficiências de alimentação e ruminação da matéria seca e FDN, animais suplementados com MON e PAP apresentaram o mesmo padrão de comportamento.
Forma de apresentação seca x líquida

Em relação aos trabalhos citados anteriormente nesta revisão, os estudos mais antigos envolvendo a imunização passiva foram conduzidos utilizando-se o PAP na forma líquida (DILORENZO et al., 2006 e 2008; OTERO, 2008; BLANCH et al., 2009; MARINO et al., 2011; PACHECO et al., 2012). Já os estudos publicados mais recentemente (BASTOS et al., 2012; BARDUCCI et al., 2009; SARTI et al., 2009; MILLEN et al., 2009; RONCHESEL et al., 2010; MARIANI et al., 2010; MILLEN et al., 2010) foram realizados com formulações do PAP na forma seca (em forma de pó).

Estudos com o PAP na forma líquida sugerem que, apesar do efeito negativo sobre o rendimento de carcaça (DILORENZO et al., 2008; PACHECO et al., 2012), animais que receberam PAP mostraram melhora no desempenho em relação a grupos controle (DILORENZO et al., 2008) e, em outros estudos, apresentaram desempenho similar àqueles animais suplementados com monensina sódica (PACHECO et al., 2012). Da mesma forma, a suplementação com PAP foi efetiva: em elevar o pH ruminal (DILORENZO et al., 2006; BLANCH et al., 2009), tanto quanto a MON (MARINO et al., 2011), e reduzir a incidência de lesões no rúmen, quando comparado à suplementação de MON (PACHECO et al., 2012).

Entretanto, quando se observam os estudos envolvendo o PAP na forma seca, os dados mostram que o PAP não foi mais tão efetivo quanto a MON para melhorar o desempenho (BARDUCCI et al., 2009) e reduzir a incidência de lesões (SARTI et al., 2009). Ainda, não foram detectados aumentos no $\mathrm{pH}$ ruminal quando diferentes doses de PAP foram testadas contra um tratamento controle (BASTOS et al., 2012). No entanto, os dados de comportamento ingestivo mostram algumas similaridades entre PAP e monensina quando estes são fornecidos a bovinos confinados (MARIANI et al., 2010).

Vale ressaltar que os estudos com PAP, na forma líquida, foram conduzidos nos EUA, Espanha e Brasil; e os estudos envolvendo o PAP, na forma seca, foram realizados somente no Brasil. Podem ser apenas experimentos “isolados”, mas é no mínimo intrigante o fato de a mudança na forma de apresentação do produto fazer com que alguns efeitos consistentemente constatados anteriormente deixassem de aparecer quando se forneceu o PAP na forma seca. No entanto, ainda não está claro se alguma etapa do procedimento, utilizado para "secar" o produto, prejudicou a atividade dos anticorpos ou os efeitos destes dentro do rúmen de alguma maneira. 
Por outro lado, pode ter acontecido que os teores energéticos das dietas utilizadas nos experimentos, bem como a formulação das dietas com o PAP, não propiciaram ambiente adequado para que os micro-organismos fermentadores de lactato e produtores de ácidos graxos de cadeia curta se desenvolvessem, para assim serem combatidos pelos anticorpos contidos no PAP. Dessa forma, a capacidade de atuação do PAP em combater esses micro-organismos maléficos e com isso propiciar melhor ambiente ruminal pode não ter sido alcançada, influenciando desse modo nos resultados das pesquisas. Assim sendo, é necessário desenvolver novas pesquisas utilizando o PAP na forma seca, em dietas mais desafiadoras energeticamente, para se tirar maiores conclusões sobre esse assunto.

\section{CONSIDERAÇÕES FINAIS}

De acordo com os resultados apresentados nesta revisão, o PAP apresenta alta especificidade com relação à população de micro-organismos ruminais, o qual elimina do meio apenas as bactérias, alvos de seus anticorpos. Em consequência disso, foi constatado aumento do $\mathrm{pH}$ ruminal a níveis adequados para fermentação benéfica, o que aumentou a população de protozoários, os quais são sensíveis a valores baixos de $\mathrm{pH}$ e, quando estão presentes no meio ruminal, exercem certo controle da fermentação, por meio da predação de bactérias e do engolfamento e liberação lenta de grânulos de amido, o que faz com que estes sejam fermentados de forma mais lenta. Dessa forma, o PAP foi efetivo em reduzir as incidências de rumenites e consequentemente de abscessos hepáticos, devido à menor acidificação do meio ruminal, o que aumentou a capacidade absortiva do epitélio do rúmen. Assim, devido aos efeitos positivos no meio ruminal, animais que consumiram PAP apresentaram maiores concentrações de bicarbonato e excesso de bases no sangue e ainda maior pH sanguíneo na fase de adaptação. Logo, a alimentação não reduz a IMS e o desempenho dos animais alimentados com rações de altos teores de concentrado é melhor, quando comparado a animais que não consomem nenhum outro aditivo alimentar, e similar àqueles que são alimentados com rações que contém monensina sódica. Com respeito ao comportamento ingestivo, as eficiências alimentação e ruminação tanto da matéria seca quanto do FDN foram similares entre animais alimentados com PAP e monensina sódica. Com relação à carne dos animais que consumiram PAP, este não afetou negativamente as características de carcaça, com exceção do rendimento de carcaça, reduzido em dois estudos, quando o PAP-Fn foi utilizado.

Por fim, a utilização de anticorpos policlonais em dietas de confinamento tem mostrado interessantes resultados no desempenho e saúde ruminal de bovinos confinados. Desse modo, mostra ser uma possível alternativa de utilização para melhorar o desempenho em confinamento e proporcionar aos nutricionistas de bovinos a possibilidade de maiores desafios frente a dietas mais energéticas, bem como possibilitar a comercialização da carne bovina em mercados que têm restrições ao uso de antibióticos na nutrição animal.

\section{REFERÊNCIAS}

BARDUCCI, R.S. et al. Feedlot performance of Brangus cattle fed monensin or polyclonal antibody preparation against lactateproducing rumen bacteria. Journal of Animal Science, v.87, E-suppl.2, p.283-284, 2009.

BASTOS, J.P.S.T. et al. Effects of adding a spray-dried polyclonal antibody preparation on ruminal fermentation patterns and digestibility of cows fed high concentrate diets. Italian Journal of Animal Science, v.11, n.4, p.431-437, 2012. Disponível em: <http://www.aspajournal.it/index.php/ijas/article/view/ijas.2012. e76/pdf>. Acesso em: 05 mar. 2013. doi: 10.4081/ijas.2012.e76.

BERGEN, W.G.; BATES, D.B. Ionophores: their effect on production efficiency and mode of action. Journal of Animal Science, v.58, p.1465-1483, 1984. Disponível em: <http:// www.journalofanimalscience.org/content/58/6/1465.full. pdf + html ?sid=c5cb6eb4-eb96-416e-8c4a-19ae05e60374> . Acesso em: 05 mar. 2013.

BERGHMAN, L.R.; WAGHELA, S.D. Antibodies: an alternative for antibiotics? Journal of Animal Science, v.82, suppl.1, p.82, 2004.

BLANCH, M. et al. Physiological changes in rumen fermentation during acidosis induction and its control using a multivalent polyclonal antibody preparation in heifers. Journal of Animal Science, v.87, p.1722-1730, 2009. Disponível em: <http:// www.journalofanimalscience.org/content/87/5/1722.full. pdf + html?sid=dd2676f1-1192-4e8c-8b0c-0277aff6745e >. Acesso em: 05 mar. 2013. doi: 10.2527/jas.2008-1184.

BURRIN, D.G. et al. Monensin level during grain adaptation and finishing performance in cattle. Journal of Animal Science, v.66, p.513-521, 1988. Disponível em: <http:// www.journalofanimalscience.org/content/66/2/513.full. pdf+html?sid=e87558a9-6b7f-49a9-b1c3-df8ae2c72fcb>. Acesso em: 05 mar. 2013.

DILORENZO, N. et al. Effects of feeding polyclonal antibody preparations on ruminal bacterial populations and ruminal $\mathrm{pH}$ of steers fed high-grain diets. Journal of Animal Science, v.84, p.21782185, 2006. Disponível em: <http://www.journalofanimalscience. org/content/84/8/2178.full.pdf+html?sid=bf639d00-e887-42118db4-cde08c34163c>. Acesso em: 05 mar. 2013. doi: 10.2527/ jas.2005-489. 
DILORENZO, N. et al. Effects of feeding polyclonal antibody preparations on rumen fermentation patterns, performance, and carcass characteristics of feedlot steers. Journal of Animal Science, v.86, p.3023-3032, 2008. Disponível em: <http:// www.journalofanimalscience.org/content/86/11/3023.full. pdf+html?sid=00b520aa-872a-49c2-adb6-3476b256089e >. Acesso em: 05 mar. 2013. doi: 10.2527/jas.2007-0859.

EIFERT, E.C. et al. Perfil de ácidos graxos do leite de vacas alimentadas com óleo de soja e monensina no início da lactação. Revista Brasileira de Zootecnia, v.35, n.1, p.219-228, 2006. Disponível em: <http://www.scielo.br/pdf/rbz/v35n1/28363.pdf>. Acesso em: 05 mar. 2013.

FELLNER, V. et al. Effect of nigercin, monensin, and tetronasin on biohydrogenation in continuous flow-through ruminal fermenters. Journal of Dairy Science, v.80, p.921-928, 1997. Disponível em: <http://download.journals.elsevierhealth.com/ pdfs/journals/0022-0302/PIIS0022030297760156.pdf>. Acesso em: 05 mar. 2013.

GOLDSBY, R.A. et al. Kuby immunology, 4.ed. New York: W.H. Freeman, 2000. Chapt.1.

GOODRICH, R.D. et al. Influence of monensin on the performance of cattle. Journal of Animal Science, v.58, p.14841498, 1984. Disponível em: <http://www.journalofanimalscience. org/content/58/6/1484.full.pdf+html?sid=b5eaf9fd-1b04-4ad5a84f-df2fe03eca65>. Acesso em: 05 mar. 2013.

HARDY, B. The issue of antibiotic use in the livestock industry: what have we learned? Animal Biotechnology, v.13, p.129147, 2002. Disponível em: <http://www.tandfonline.com/doi/ abs/10.1081/ABIO-120005775>. Acesso em: 05 mar. 2013. doi: 10.1081/ABIO-120005775

MARIANI, T.M. et al. Effects of feeding polyclonal antibody preparations against lactate-producing rumen bacteria or monensin on feeding behavior of feedlot cattle. Journal of Animal Science, v.88, E-suppl.2, p.709, 2010.

MARINO, C.T. et al. Effects of adding polyclonal antibody preparations on rumen fermentation patterns and digestibility of cows fed different energy sources. Journal of Animal Science, v.89, p.3228-3235, 2011. Disponível em: <http:// www.journalofanimalscience.org/content/89/10/3228.full. pdf +html? sid=50ed86c6-6a74-4abe-bf86-79538b1b31cd > . Acesso em: 05 mar. 2013. doi: 10.2527/jas.2010-3062.

MILLEN, D.D. et al. Feedlot performance of Nellore and Brangus cattle fed monensin or polyclonal antibody preparation against lactate-producing rumen bacteria. Journal of Animal Science, v.87, E-suppl.2, p.282, 2009

MILLEN, D.D. et al. Effects of feeding polyclonal antibodies preparations against lactate-producing rumen bacteria or monensin on blood gas profile, DMI fluctuations and rumenitis incidence of feedlot cattle. Journal of Animal Science, v.88, E-suppl.2, p.709, 2010.

NEWBOLD, C.J. et al. Developments in rumen fermentation The scientist's view. In: GARNSWORTHY, P.C.; WISEMAN, J. (Ed). Recent advances in animal nutrition 2001. Nottingham, United Kingdom: Nottingham University, 2001. p.251-279.

OTERO, W.G. et al. Rumen microbial diversity under influence of a polyclonal antibody preparation against lactate-producing and proteolytic bacteria in cows fed different energy sources. Revista
Brasileira de Saúde e Produção Animal, v.13, n.2, p.491-502, 2012. Disponível em: <http://revistas.ufba.br/index.php/rbspa/ article/view/2185/1259>. Acesso em: 05 mar. 2013.

PACHECO, R.D.L. et al. Effects of feeding a multivalent polyclonal antibody preparation on feedlot performance, carcass characteristics, rumenitis, and blood gas profile in Bos indicus biotype yearling bulls. Journal of Animal Science, v.90, p.18981909, 2012. Disponível em: <http://www.journalofanimalscience. org/content/90/6/1898.full.pdf+html?sid=bf639d00-e887-42118db4-cde08c34163c>. Acesso em: 05 mar. 2013. doi: 10.2527/ jas.2010-3521.

RONCHESEL, J.R. et al. Effects of feeding monensin or polyclonal antibody preparation against lactate-producing rumen bacteria on blood lipoprotein concentrations of feedlot cattle. Journal of Animal Science, v.88, E-suppl.2, p.709, 2010.

RODRIGUES, E. et al. Performance, carcass characteristics and gain cost of feedlot cattle fed a high level of concentrate and different feed additives. Revista Brasileira de Zootecnia, v.42, n.1, p.61-69, 2013. Disponível em: <http://www.scielo.br/pdf/rbz/ v42n1/v42n1a09.pdf>. Acesso em: 05 mar. 2013.

SARTI, L.M.N. et al. Rumen papillae measurements of feedlot cattle fed monensin or polyclonal antibody preparation against lactate-producing rumen bacteria. Journal of Animal Science, v.87, E-Suppl.2, p.284, 2009.

SAUER, F.D. et al. Methane output and lactation response in Holstein cattle with Monensin or unsaturated fat added to the diet. Journal of Animal Science, v.76, p.906-914, 1998. Disponível em: <http://www.journalofanimalscience.org/content/76/3/906. full.pdf+html?sid=ecf2a55a-8d33-4132-8763-6b4b41c639f5> Acesso em: 05 mar. 2013.

SHIMIZU, M. et al. Anti-E. coli immunoglobulin Y isolated from egg yolk of immunized chickens as a potential food ingredient. Journal of Food Science, v.53, p.1360-1366, 1988. Disponível em: $<$ http://onlinelibrary.wiley.com/doi/10.1111/j.1365-2621.1988. tb09277.x/pdf>. Acesso em: 05 mar. 2013.

SHIMIZU, M. et al. Molecular stability of chicken and rabbit immunoglobulin G. Bioscience Biotechnology Biochemistry, v.56, p.270-274, 1992. Disponível em: <https://www.jstage.jst. go.jp/article/bbb1992/56/2/56_2_270/_pdf>. Acesso em: 05 mar. 2013

SHU, Q. et al. Immunization with a Streptococcus bovis vaccine administered by different routes against lactic acidosis in sheep. Veterinary Journal, v.159, p.262-269, 2000. Disponível em: $<$ http://www.deepdyve.com/lp/elsevier/immunization-with-astreptococcus-bovis-vaccine-administered-by-5BESRPX5NP/1>. Acesso em: 05 mar. 2013.

STOCK, R.A. et al. Effects of monensin and monensin and tylosin combination on feed intake variation of feedlot steers. Journal of Animal Science, v.73, p.39-44, $1995 . \quad$ Disponível em: <http://www.journalofanimalscience.org/content/73/1/39.full. pdf + html?sid=17fd3aef-ad85-4537-a14b-72ceec92e777>. Acesso em: 05 mar. 2013

VAN NEVEL, C.J.; DEMEYER, D.I. Lipolysis and biohydrogenation of soybean oil in the rumen in vitro: Inhibition by antimicrobials. Journal Dairy Science, v.78, p.2797-2806, 1995. Disponível em: <http://download.journals.elsevierhealth. com/pdfs/journals/0022-0302/PIIS0022030295769107.pdf >. Acesso em: 05 mar. 2013. 